Revista Signos

2008, 41(68)

$423-437$

\title{
Analysis of the organizational and informational value of links in psychology and geology popular science hyperarticles
}

\author{
Andrea Puchmüller \\ Marcela Puebla \\ Universidad Nacional de San Luis \\ Argentina
}

\begin{abstract}
Genre analysis has greatly influenced the teaching and learning of English for Specific Purposes (ESP). Because of its impact, the Internet has become an interesting setting to study the use and development of genres and to assist learners in understanding hypertexts as well as their distinctive element: the link. Following Hammerich and Harrison's taxonomy (2002), this article analyzes the organizational and informational value of this key element in psychology and geology articles. The study revealed that, from the organizational angle, there might be a tendency to economize on the use of strongly authored links, and that, from the organizational angle, the enhancing function was found most frequently, thus limiting the multimedia potentialities of this environment to personalize texts. This might indicate that, in the sample of hyperarticles, there is a strong bias toward economizing some of the features that make hypertexts unique and distinctive.
\end{abstract}

Key Words: Popular science hyperarticles, link, organizational value, informational value.

Recibido: 22-V-2007 Aceptado: 25-IV-2008
Correspondencia: Andrea Puchmüller (puchmuller@yahoo.com.ar). Tel.: (54-02652-435512 anexo 103). Centro de Lenguas Extranjeras (CELEX), Facultad de Ciencias Humanas. IV Bloque, Universidad Nacional de San Luis, Ejército de Los Andes 950 (5700) San Luis, Argentina. 


\section{Análisis del valor organizativo e informativo de los links en hiperartículos de divulgación científica en el campo de la Psicología y la Geología}

Resumen: El análisis del género ha influenciado significativamente la enseñanza y el aprendizaje del Inglés para Propósitos Específicos (I.P.P.E.). En la actualidad, dado el impacto de la internet, la web se ha convertido en un espacio interesante en el cual estudiar el uso y desarrollo de los géneros para ayudar a los estudiantes a conocer el hipertexto y su elemento característico: el link. El propósito de este trabajo es analizar el valor organizativo e informativo de este elemento clave en hiperartículos en el área de la Psicología y Geología a partir de la taxonomía propuesta por Hammerich y Harrison (2002). El estudio reveló que, desde el punto de vista organizativo, habría una tendencia a economizar el uso de links 'especialmente creados' y, desde el punto de vista informativo la función más encontrada fue la de 'ampliación de la información', limitando así las potencialidades multimediales de este medio para personalizar hipertextos. Esto indicaría una fuerte tendencia en los hipertextos de Psicología y Geología de la muestra a economizar algunas de las características que hacen a los hipertextos únicos y distintivos.

Palabras Clave: Hiperartículo de divulgación científica, link, valor organizativo, valor informativo.

\section{INTRODUCTION}

Genre analysis has become one of the major influences on the current practices in the teaching and learning of languages, in general, and in the teaching and learning of ESP, in particular (Bhatia, 2005).

"ESP... is a linguistic approach applying theories of functional grammar and discourse and concentrating on the lexical-grammatical and rhetorical realization of the communicative purposes embodied in a genre... with an additional interest in organizational patterns at the discourse level” (Johns, 2002: 91).

Genre knowledge can assist learners in developing an understanding of texts that can serve them throughout their academic and professional lives. Nowadays,

"the web has become a particularly interesting setting in which to study the use and development of genres and genre repertoires... because there are many communities meeting on the Web, bringing experiences with different genres and using it for many different purposes" (Crowston \& Williams, 1998:2-3).

Therefore, many studies concerning this new computational environment have focused mainly on the genres and their similarities and differences with the genres in traditional environments.

These investigations have brought about the study of the distinctive element of the hypertext, namely, the link. Lewis et al. (1999) explored the history of links and drew a distinction between navigation and retrieval in information handling. Hammerich and Harrison (2002) studied the 
nature of the semantic relationships and rhetorical principles underlying link development and proposed a classification of link types from business websites for researchers and Web production teams. However, to the best of our knowledge, no study has been carried out concerning the characteristics of links in popular science hyperarticles.

The main purpose of the present work is to analyze the organizational and informational value of what we consider the key element that makes a hypertext different from other texts: the link in psychology and geology hyperarticles. This paper follows the Introduction-Method-Results-Discussion structure described by Swales (1990) and within the Introduction it presents a theoretical background to provided a context for the research.

\section{Theoretical background}

\section{1. Digital Genres}

The growing digitalization of communication and the dominance of the Internet in the 90 's has extended the field of genre study to digital genres. Crowston and Williams (1998) were among the first to see the importance of the study of genres for analyzing communication on the Internet because of easy access, freedom of structuring and interaction between many communities. They studied randomly selected 1000 web pages and based their distinction on purpose. They identified forty eight different genres and categorized them as: 1. familiar or reproduced genres; that is, existing genres such as a book or an academic article, that have been moved intact to the web; 2 . adapted or new, but accepted genres which were described as those which had undergone certain changes to introduce the links and, since repeatedly used, have become accepted as, for example, the journal article; 3. new or novel genres described as those that have emerged as a distinct genre like FAQs or homepages and; 4. unclassifiable, category in which those genres that were in the process of adaptation to the web (variants of an accepted genre, but with some features missing) were included.

Yates and Orlikowski (in Breure, 2001:7) also

"(...) applied the notion of genre to organizational communication... and studied, among others, the evolution from the formal business letter to electronic mail. They analyzed the genre repertoire in the e-mail of a team of computer language designers, paying attention to the function of memos, language proposals, dialogs and ballots. In accordance with modern genre theory, these authors see genres as socially recognized types of communicative actions, and identify them by their purpose and by their common characteristics of form".

They suggest that "...communications in a new media show both reproduction or adaptation of 
existing communicative genres as well as the emergence of new ones" (in Crowston \& Williams, 1998:1).

The term 'cybergenre', coined by Shepherd and Watters (1998, in Breure, 2001), denote digital genres. These authors classify them into two categories:

- Extant subgenres: based on genres existing in other media which have migrated to a computer environment and are faithfully replicated without fully exploiting the capabilities of the new medium. Examples of these are: newspapers, dictionaries, biographies and research articles.

- Novel genres: wholly dependent on the new medium and could not exist in another one. Examples of these are: hyperfiction, home pages or virtual games.

In addition, Yates and Sumner (1997, in Breure, 2001) point that the notion of genres provides a certain degree of stability and fixity since the combination of content and form gives a familiar reference to users. According to this categorization, popular science hyperarticles, the genre under study in this paper, falls into the category of extant subgenres.

\subsection{Popular science articles}

Science popularization is an activity which has grown considerably with the expansion of popular magazines, newspapers and the World Wide Web. Popularization means recontextualizing scientific knowledge to convey it to wider audiences (Calsamiglia, 2003). Loffler-Laurian (1983, in Gallardo, 1998) propose a division of popular science articles based on the communication system, the characteristics of the writer and the reader, and the nature of the message media. This categorization includes:

a. Specialist popular science articles: issued in popularization magazines restricted to specialists, being the reader and the writer specialists.

b. Semi-popular science articles: released in magazines that cover different topics and written by professional specialists but directed to non-specialist graduates who know about the subject matter.

c. Popular science articles: published in special newspaper and magazine supplements that are easily accessed at low cost. They are written by a science professional journalist who aims at reaching a lay audience.

All in all, it could be said that the popularization of science includes texts about science that are addressed to non-specialists or the general public who want to know about the major scientific breakthroughs, their applications, utility and consequences of their use in people's lives (Myers, 
2003). Therefore, popularization has helped to reduce the gap between the scientific world and the world of ordinary everyday experience, which used to be evident in the differences between scientific discourses and its everyday counterpart (Calsamiglia, 2003).

\subsection{Hypertext}

Hypertext is an old and a new concept. It is old in the sense that this technological change merely foregrounds aspects of texts which have always been present. In a book, for example, foot notes or cites perform the same function as the hypertext link by directing the reader to other documents. Intertextual features like quotations are another example that reveals the impulse to go beyond strict unity, sequence and closure creating thus a cognitive hypertext because the relations established depend on the readers' schemata or prior knowledge. It is new in as much as it designates a technological revolution in textual media and describes text chunks that are connected by links which offer the reader different pathways. The user may then browse through the sections of the texts and jump from one text section to another according to his/her interests (Foltz, 1996). Thus, this new technology has facilitated, made more transparent and turned into something physical the link, which has always been a feature of the process of reading.

\subsection{Links}

Hyperlinks are the elements that define web-based texts and allow multiple texts to be connected. These connections make the web a different medium of communication by relating a text to another text, a text to a song, a text to a graphic, establishing "...a relationship that is semantic by nature and rhetorical by purpose" (Harrison, 2006:9). In the 1980s, links were designed and created by the author of the hypertext and were permanently fixed to the documents they referred to. However, links have evolved in a variety of ways and achieved their popularity on the Internet. In some systems links are held in link databases separately from the document to which they refer (Lewis, 1999). The evolution of the links brought about a vast classification of hyperlinks according to different and varied criteria. For instance, Lewis et al. (1999) classify them according to the hypermedia system design as static, i.e., point-to-point connections that are fixed and embedded in a hypertext and dynamic, i.e., built into link databases and separate from the documents to which they refer.

Based on the same criterion, Hammerich and Harrison (2002) differentiates between explicit links, i.e., obvious to the user, or implicit links, i.e., built in as part of the structure of the hypertext design model. However, she points out that the underlying basic feature of all systems is the difference between strongly authored links -manually made- and weakly authored links- 
built through computational models. To put it in other words, this means that in the processes of developing web sites professional writers may decide to design a link exclusively written for his/her particular hypertext or may create one between his/her hypertext and another page that contains related information. In order to make decisions, writers and designers on the web "imagine the audience and draw on their internal representation of the possible reader as a guide to writing and designing" (Dotto, 2006:3).

In addition to the former categorization derived from business websites, Hammerich and Harrison (2002) suggest the following taxonomy of links that has to do with the kind of information they provide, though they observe that:

"... no hypertext -whether static or dynamic, strongly or weakly authored- can be divorced from the subjectivity of human choice";

- authorizing links: provide access to an organization's official, legal and formal information that helps to authenticate a site, as in the links "About us" or "Customer Service Policies";

- commenting links: provide opinion about the site and/or its content; for example, links to expert or consumer reviews of a company's products or services or links to opinion articles and columns;

- enhancing links: offer greater details and factual information about the site content. It includes any link that leads the reader to guidelines, information, descriptions, as in the links "Site Map" or "Guidelines for Membership";

- exemplifying links: are the on-line equivalent to the print phrase "for example" or "for instance". They provide specific examples of content within a broader category, as recipes on a cooking or gourmet site or the trailer for a movie on a movie production site;

- mode-changing links: move users from the reading mode to one that requires a different kind of activity, such as taking a quiz, playing a game or completing an on-line survey;

- referencing/citing links: provide information that "informs" or supplement the site's content, as in the links "Bibliography" or "Related Links";

- self-selecting links: allow users to narrow a search by making choices based on their age, sex, geographical location, life situation, personal interests, and so on. This type creates the logical "If...then" relationship, for example: "If you are looking for....then click here". An example is the section of e-commerce sites that allow transactions such as an airline's online reservation service where users narrow down their choices by clicking on different destinations, times, and so on.

According to the degree of coherence established by lexical repetition among the different 
levels of a computational hypertext, Puebla and Puchmüller (2006) classify links from a corpus made up of hyper-biographies into:

- Central links: those that establish three or more lexical networks with the other levels of the hypertextual system (intermodal relations). These links are said to be highly informative and to contribute crucially to the development of the theme of the hypertext.

- Marginal links: those that do not share lexical connections with the hypertextual level containing them, or at least not enough connections to establish a lexical network with other levels. Their informational value is null in relation to the level in which they are inserted, i.e. they do not contribute to the development of the theme of the hypertext and many times offer information not related to it.

- Intermediate links: those that form one or two lexical intermodal networks, providing a lesser degree of cohesion to the hypertextual level that contains them than the central links, but greater than the marginal ones. The importance of the information they contain will depend on the reader's background knowledge and his capacity to establish semantic connections with the other levels of the system.

- Hypertextual conventions: those links that are standard to all hypertextual systems, such as "click here", "send us e-mail", "FAQ", etc.

\section{Method}

This work is framed in the Research Project "Genre-based Pedagogy" of the Science and Technology Office, from the National University of San Luis. As researchers and teachers of ESP of the Faculties of Humanities and Physics and Maths of the above mentioned university, our main aim was to make a research on the characteristics of the links included in Geology and Psychology popular science hyperarticles.

Although science textbooks and research articles are target forms for students at university level, popular science articles were chosen for the study of their links for two reasons: first, because with the increasing use of the internet it has become one of the genres our students have started to read more frequently; and second, because we consider this genre useful for students since they bring up familiarity with lexical items and content of their disciplines.

The starting point for the corpus collection was to observe which popular science hyper-magazines or websites the students consulted as sources of information for their ESP classes. These on-line-magazines were: LiveScience, Geotimes, National Geographic, Creation-Evolution Headlines, Psychology Today, ScienceDaily and American Psychological Association; and the website 
KidsHealth that provides information addressed to the general public. To corroborate the reputation of these magazines and website as organs for the popularization of scientific research findings, we consulted the links "About Us" in each of them. The criterion for building up the corpus was that they contained at least three links in the first level. The magazines whose hyperarticles met this requirement were LiveScience and Geotimes for Geology and ScienceDaily and the KidsHealth website for Psychology. The gathering of the corpus of popular science hyperarticles was carried out at random from November 2004 to May 2006. Thus, these four sources provided a 24 hyperarticle corpus with a total of 62 static links.

To analyze the hyperlinks, the categories concerning the organizational and informational aspects of the links claimed by Hammerich and Harrison (2002) were followed. These taxonomies stem from these authors' experience in developing web sites for the government, the private section and business sectors. On the one hand, from the organizational point of view, Hammerich and Harrison (2002) differentiate between strongly authored links; that is, manually made and weakly authored links; namely, made by computational models. On the other hand, from the informational point of view, they distinguish among authorizing, commenting, enhancing, exemplifying, mode-changing, referencing/citing and self-selecting links.

Once the hyperarticles were selected, the three first links in each hypertext were visited to determine whether they had been especially created by the designer to expand on information; i.e. if they were strongly authored, or if they had just been connected to another hypertextual system. The same process was carried out to assess the informational load of the links; that is, the first three links were visited and then analyzed according to Hammerich and Harrison's taxonomy.

\section{Results}

From their organizational point of view, the analysis of the 36 hyperlinks from the field of psychology revealed differences between the two sites chosen. From the links included in the hypertexts downloaded from the website KidsHealth two were weakly authored because they took the reader to other sites which provided information about Clinics or Health Centers, and sixteen were strongly authored, that is, the lexical items were used to connect the hypertext to another hypertext, with the same kind of information, within the same web site. For example, the first link "attention deficit hyperactivity disorder" in the hypertext "The effects of adolescent mental disorder last into adulthood" connected the user to another hypertext which provided an introduction, definition, causes and consequences of such disorder.

However, the 18 links studied from the online magazine ScienceDaily were weakly authored, that is to say, all of them established connections with other hypertextual systems which were 
not at all useful for the development of the topic. For example, the link "Mental illness" in the article "Suicide in one partner substantially increases suicide risk in the other" connected the hipertext to "Kosamba" an institution offering professional counselors. As far as the informational value was concerned, sixteen hypertexts downloaded from KidsHealth website displayed the enhancing function. They laid factual information for the user by linking the hyperarticle to other hyperarticles whose content added more detailed information. For instance, in the hyperarticle "Teen boys with anorexia have distorted body image" the link "eating disorder" provided a hyperarticle with the same degree of information as the hyperarticle that contained the link. The other two links were self-selecting since they offered the users the possibility of narrowing down their search by making choices based on their own interests. For instance, in the hypertext "The effect of adolescent mental disorder last into adulthood" the link "Asthma" directed the reader to an Asthma Center, that provided educational and professional advice about the problem, but did not explain what asthma means, its causes and consequences.

As regards the findings from the Science Daily magazine the eighteen links were self-selecting. For example, the link "body fat" in the hypertext "Anorexia nervosa often chronic, study finds" advertised an all-natural fat burner, creating in this way the logical "if... then..." relationship, which in this case implicates "if you are fat, buy this product".

Concerning the organizational value of the 36 hyperlinks belonging to the geology on-line magazines, only six of them corresponded to the category of strongly authored. These were links which mainly referred to visual aids such as maps and photographs. For example, the link "ring of fire" from the article "Indonesian volcano: Ready to erupt" (Geotimes) included a photo illustration of the chains of volcanoes and oceanic trenches of Indonesia. In like manner, in the article "Hurricane alley heats up" (Live Science), the link "Hurricanes from above" displayed different hurricanes photographed from different perspectives. The remaining 30 links studied were weakly authored, thus creating a connection with other hypertextual systems. Such was the case of the link "San Francisco Convention and Visitors Bureau" in the article "10 Years After San Francisco Quake" (Geotimes) which established a bond with the official site of San Francisco city. Or the connection set up by the link "Geotimes, April 2006" in the hyperarticle "Yellowstone moving magma" which presented another article called "Italy's hidden hazard", belonging to the same magazine.

From their informational point of view, 22 links of the geology on-line magazines were enhancing since they provided more factual information about the site contents by offering greater detail. For example, the link "Develop into a hurricane" from the article "Hurricane alley heats up" led to a description and an explanation of how and where hurricanes form. The Geotimes hyperarticle "Mineralogy: Cooked minerals resemble life" contained, for example, the link "Laboratory experiments" which included another article with more detailed information about astrobiology. 
Eight links were mode-changing, moving users from the reading mode to one that required a different kind of skill or cognitive ability. Such was the case of the link "The bulge seen in 2001 Satellite Data" in "Mystery bulge in Oregon still growing" (Live Science), which presented a picture showing a satellite radar interferogram of a rocky bulge. In Geotimes, the article "Italy's hidden hazard" displayed a link called "Print exclusive" which would require the reader to read and fill in an on-line subscription form to buy the magazine. The six remaining links were selfselecting since they created the already mentioned "if...then..." relationship. Such was the case of the link "Vulcania" (in "Auvergne: Hidden hotspot", Geotimes) which advertised a volcano theme park in Auvergne, allowing the reader to narrow his/her choices by finding information on timetables, rides, ticket rate, food, so on. Something similar occurred with the link "Cable car museum" (in "10 years after San Francisco quake", Geotimes) which advertised the museum and supplied similar information categories than the latter link mentioned.

\section{Discussion}

The reasons behind for studying the organizational and informational value of the links were that these devices are the distinctive characteristic of the computational environment; that is, they are lexical items explicitly chosen to create a connection to another item of information.

As can be observed from the findings, the way web designers interconnect hypertexts varies significantly from site to site. As regards the organizational point of view, Hammerich and Harrison (2002) from their study of business websites, proposed a classification of links that comprised two categories: strongly and weakly authored. Likewise, the same categories were found in our study. Out of the seventy two links analyzed, fifty were weakly authored and twenty two corresponded to the strongly-authored category. In the psychology hyperarticles, sixteen links were strongly authored and these belonged to the Kids Health website. The fact that all the strongly authored links were found in this website, might be because it is a site especially designed to provide families with accurate, up-to date doctor-approved health information about children and adolescents. That is, they have been designed with the aim of supplying specialized information to parents, teens and children. On the contrary, the eighteen links studied from the ScienceDaily online magazine were weakly authored, probably because their main purpose is not to go deeper into the topic but enable user access to other databases such as leading universities and other research organizations around the world. This finding may also indicate that the importance is given to the breaking news about the latest discoveries and hottest research projects not to definitions, exemplification or other rhetorical devices used to help the reader understand the text.

In the geology hyperarticles, thirty out of the thirty six links analyzed were weakly authored and the remaining six links were strongly authored. This might reveal a tendency of link designers or 
writers of geology hypertexts to simply connect web pages and not to design specific links that would provide the hypertext the possibility of presenting further information, exemplifying, commenting or citing.

As regards the informational value, Hammerich and Harrison (2002) found in their study of business websites seven different kinds of links: authorizing, commenting, enhancing, exemplifying, mode-changing, referencing/citing and self-selecting. Nevertheless, in this analysis of psychology and geology hypertexts only 3 of these categories were found: 38 were enhancing, eight were mode-changing and 26 were self-selecting. The findings show, therefore, that the enhancing links were the most recurrent type in the corpus analyzed, sixteen belonging to the psychology hypertexts and twenty two to the geology ones. The number of enhancing links found in the psychology website "KidsHealth" (16) coincided with the 16 strongly-authored links in the same site. As said before, this might be due to the nature of the website: a site especially designed to provide parents, children, and adolescents with specialized information. Although this one-toone correspondence was not found in the geology hypertexts, there also seemed to be a certain tendency of strongly authored links to perform an enhancing function.

It was also observed that mode-changing links which were expected to be the most common type of connection -due to the virtual environment nature- were, in fact, the less frequent ones. This kind of links realize one of the most significant characteristics of hypertexts, since they

"...move users from the reading mode to one that requires a different sort of activity, such as taking a quiz, undertaking an exercise, playing a game, listening to a song, completing an on-line survey, or filling out a form" (Harrison, 2006:12).

The only mode-changing links were found in geology hypertexts, and these contained only static visual aids (maps and pictures). This might mean that although only a few mode-changing links were found, there would be a trend in geology hypertexts to establish visual-verbal relationships by means of links.

In reference to the self-selecting function, the links that displayed it were mainly found in the psychology hyperarticles downloaded from the ScienceDaily magazine (18). This may be because this magazine is aimed at providing popularized information as well as advertizing products, places, treatments etc. In the geology hypermagazines, there seemed to be a predisposition of not including e-commerce, transactional or advertizing links but simply providing information to the lay public.

These findings would therefore indicate a tendency in the writers and editors of this kind of hypertexts to just connect web documents and not to design specific links that the hypertext proper might require to broaden and/or clarify information, to exemplify, to comment, to cite etc. This may mean that it would depend on the reader's goals, background knowledge and 
skills, which of these features to use and which to discard.

The present study has shown that the popular science hypertexts analyzed do not fully exploit the potentialities of this cybergenre. Hypertext specialized literature tells us that hypertexts have incorporated many new features that are not found physically explicit in linear texts, such as links and the use of multimedia. There is a great deal of potential for hypertext systems in blending texts with sound archives, static and dynamic images, guided tours, overview maps, search engines, additional texts etc. However, in the corpus studied only a minority of the hypertexts presented graphics, maps or other visual elements (also found in linear environments) and none made use of sound or video. This might indicate a strong bias in economizing some of the features that make hypertexts unique and distinctive. Moreover, by reducing the potential offers of hypertexts, the possibilities of personalizing them are also diminished, since there seems to be no exhaustive evaluation of what different kinds of readers might need and know. Designing a hypertext is not just a matter of connecting one text to another. As seen from the results of this study, the hypertexts of the corpus do not seem to develop fully appropriate user models, since they are too frugal on the use of strongly authored links and links with a modechanging function.

\section{Limitations of the study and conclusion}

This study has focused solely on textual analysis. The decision on what to include in a hypertext is always based on human choice, which is inherently idiosyncratic. Therefore, an interesting area for further research would be to peruse the rhetorical reasons that lead writers, editors and designers of hypertexts to make the link decisions.

A further question that also remains is whether the differences found in those links belonging to the website on psychology and the magazine of the same field, are due to the nature of the two genres.

Likewise, further studies should be carried out with a larger corpus of hyperarticles and links in other fields.

\section{REFERENCES}

Bhatia, V. (2005). Applied genre analysis and ESP. Functional approach. Section 4, Genre Approaches 10 [on line]. Available in: http://exchanges.states.gov./education/engteaching/pubs/BR/ functionalsec4_10.htm

Breure, L. (2001). Development of the genre concept. University of Utrecht, Department of Information and Computing Sciences [on line]. Available in: http://www.cs.uu.nl/people/leen/GenreDev/GenreDevelopment.htm 
Calsamiglia, H. (2003). Popularization discourse. Discourse studies, 5 (2), 139-146.

Crowston, K. \& Williams, M. (1998). Reproduced and emergent genres of communication on the World Wide Web [on line]. Available in: http://crowston.syr.edu/papers/genres-journal.html

Dotto, L. (2006). Writing science articles for the internet [on line]. Available in: www.spacenet. on.ca/stories/iwmanual/index.htm

Foltz, P. (1996). Comprehension, coherence and strategies in hypertext and linear text [on line]. Available in: http://www-psych.nmsu.edu/ pfoltz/reprints/Ht-Cognition.html

Gallardo, S. (1998). Estrategias y procedimientos de reformulación de textos de divulgación científica. Revista de la Sociedad Argentina de Lingüística, RASAL; 68-79.

Hammerich, I. \& Harrison, C. (2002). Developing online content: The principles of writing and editing for the web. New York: John Wiley \& Sons.

Harrison, C. (2006). Hypertext links: Whither thou goest, and why. First Monday. Peer Reviewed Journal on the Internet. ISSN 1396-0466. University of Illinois at Chicago Library [on line]. Available in: http://www.uic.edu/depts/lib/

Johns, A. (2002). Genre in the classroom. New Jersey: Earlbaum, Publishers.

Lewis, W., Hall, L., Carr, A. \& De Roure, D. (1999). The significance of linking. ACM Computing surveys, 31 (4). [on line]. Available in: http://www.cs.brown.edu/memex/ACM_HypertextTestbed/papers/20.html

Myers, G. (2003). Discourse studies of scientific popularization: Questioning the boundaries. Discourse Studies, 5 (2), 265-278.

Puebla, M. \& Puchmüller, A. (2006). Implicancias de la repetición léxica en la lectura del hipertexto computacional (género biografías). Diálogos pedagógicos, 53-64.

Swales, J. M. (1990). Genre analysis. United Kingdom: Cambridge University Press.

\section{CORPUS}

\section{Live Science online magazine}

1. "Hurricane Alley heats up"

http://www.livescience.com/forcesofnature/060502_hurricanes_water.html

2. "Mystery bulge in Oregon still growing"

http://www.livescience.com/environment/ap_050906_sisters_bulge.html

3. "Hurricane Beta sets record for most in a season"

http://www.livescience.com/forcesofnature/ap_051029_hurricane_beta.html

4. "Wilma's rage suggests new hurricane categories needed"

http://www.livescience.com/forcesofnature/051020_hurricane_winds.html

5. "Auvergne: Hidden spot"

http://www.livescience.com/forcesofnature/ap_050731_hurricanes_stronger.html 
6. "How \& where hurricanes form"

http://www.livescience.com/forcesofnature/hurricane_formation.html

\section{Geotimes online magazine}

7. "Yellowstone moving magma"

http: / /www.geotimes.org/current/NN_Yellowstone.html

8. "10 Years after San Francisco Quake"

http: / /www.geotimes.org/apr06/Travels04066.html

9. "Indonesian Volcano: Ready to erupt"

http://www.geotimes.org/current/NN_seawater.html

10. "Mineralogy: Cooked minerals resemble life"

http: / /www.geotimes.org/jan05/NNcookedminerals.html

11. "Italy's hidden hazard"

https://store.agiweb.org/geotimes/

12. "Auvergne: Hidden spot"

http://www.google.com.ar/search?hl=es\&q=Auvergne\%3A+hidden+spot\%2BGeotimes\&btnG= Buscar\&meta=

\section{KidsHealth web site}

13. "The link between intelligence and suicide risk" http://kidshealth.org/research/intlligence_suicide-link.html

14. "Teen boys with anorexia have distorted body image" http://kidshealth.org/research/boys_anorexia.html

15. "The effect of adolescent mental disorder last into adulthood" http: / /kidshealth.org/research/effects_mental.html

16. "FDA to put strongest warning labels on antidepressants" http:/ / kidshealth.org/research/fda_antidepressants_label.html

17. "Talking to your child about puberty" http: / /kidshealth.org/parents/growth/growing/talk_about_puberty.html

18. "Kids who were breastfed less likely to wet the bed" http://kidshealth.org/research/breastfeeding_bedwetting.html 


\section{ScienceDaily online magazine}

19. "Anorexia nervosa often chronic, study finds" http://www.sciencedaily.com/releases2005/07/050708055534.htm

20. "Study finds surprising links between depression, suicide and epilepsy" http://www.sciencedaily.com/releases2005/10/051010085822.htm

21. "Suicide in one partner substantially increases suicide risk in the other" http://www.sciencedaily.com/releases2005/06/05061912322.htm

22. "Mayo Clinic study suggests no link between autism and immunization" http: / / www.sciencedaily.com/releases/2005/01050110114832.htm

23. "Blod clots may hold key to treating dementis" http:/ / www.sciencedaily.com/releases/2006/04/060428151755.htm

24. "Adults also suffer from cyclicalvomiting syndrome" http://www.sciencedaily.com/releases/2005/12/051227111834.htm 